\title{
Structural and Magnetic Properties of Duplex Stainless steel (UNS S31803) Powders Obtained by high Energy Milling of Chips with Additions of NbC
}

\author{
Claudiney de Sales Pereira Mendonça ${ }^{a *}$, Adhimar Flávio Oliveira ${ }^{a}$ Leonardo Albergaria Oliveira
}

\author{
Manoel Ribeiro da Silva ${ }^{a}$,Mirian de Lourdes Noronha Motta Melo ${ }^{a}$, Gilbert Silva ${ }^{a}$ \\ ${ }^{a}$ Universidade Federal de Itajubá,. Av. BPS, 1303, Pinheirinho, Itajubá, MG, Brasil
}

Received: August 07, 2017; Revised: September 29, 2017; Accepted: October 05, 2017

\begin{abstract}
In this study, the high energy mechanical milling was utilized to the production of duplex stainless steel powders from the recycling chips with and without the addition niobium carbide. The effect of milling time and addition carbide on the morphology, particle size and magnetic properties of the powders was investigated. The utilization of the powder metallurgy constitute an important alternative for the reuse of waste in the industrial sector. The milling was realized using a planetary ball mill for 20 hours at a milling speed of $350 \mathrm{rpm}$ and ball-to-powder weight ratio of 15:1were used, and the $(0 \%$ and 3 wt. $\%)$ niobium carbide $(\mathrm{NbC})$ addition. Scanning electron microscopy and particle distribution analysis were used for characterization of morphology and measure of particle size. Also, to analyze the transformations of phases were investigated using the magnetic characterization and $\mathrm{x}$-ray diffraction. The results indicated that the addition of niobium carbide results in the reduction of the particle size of steel of the order of $20 \%$, besides the reduces the transformation of austenite into strain induced martensitic phase.
\end{abstract}

Keywords: chips, Duplex stainless steel, morphology, magnetic properties, mechanical milling, particle size, niobium carbide, martensite

\section{Introduction}

The utilization of stainless steel has been increased extensively in various fields in the past few decades ${ }^{1}$. Duplex stainless steels (DSS) are characterized by a biphasic structure, constituting an approximate equal amount of ferrite $(\alpha)$ and austenite $(\gamma)$. The ferrite phase is responsable for an increased resistance, while the austenite phase ensures the toughness and better corrosion resistance ${ }^{2-4}$.

At the end of the useful life of a mechanical component it is discarded in deposits or remelted, making this cycle costly for industry, while the discarding brings environmental problems. The increase in energy costs and raw materials used in the manufacturing processes, which have been verified in recent years, have led the researchers to develop new methods of obtaining these materials, an alternative is to reuse machining chips as raw material to manufacture new components mechanics ${ }^{5,6}$. Recycling is widely used in metallic materials. A cleaner production of the reuse of materials is the use of powder metallurgy processes that offer advantages in relation to the conventional process, such as in the production of small parts of complicated shapes, generally of motors and gears 7 . This option becomes an advantageous technique, since $95 \%$ of the machined metal chips can be recovered ${ }^{8}$.

In a recent work, it was verified that the addition of niobium carbide in the process of high energy milling of

*e-mail: claudiney.sales@unifei.edu.br chips of the machining process increases the efficiency of the milling process, with a greater decrease of the size of the particles, obtaining nanometric particles ${ }^{9,10}$. The carbides have attracted interest because of their exceptional mechanical, physical and chemical properties, such as high temperature stability, high hardness, and good electrical and thermal conductivity ${ }^{11,12}$. The niobium carbide presents a high hardness and toughness, elevated Young's modulus and a high melting point, above $3000^{\circ} \mathrm{C}^{12,13}$. In stainless steel, niobium forms dispersed micro- or nano-sized niobium carbide particles, controlling the microstructure and thus improving mechanical properties $^{14,15}$. Furthermore, Brazil has the largest reserves of niobium in the world, which makes this strategic study for Brazil ${ }^{14}$.

The process of Mechanical milling (MM) utilizes high frequency and high energy impacts causing severe plastic deformation, repeated fracturing and cold welding of the particles ${ }^{16-18}$. Due to this, the mechanical milling process can lead to changes in the microstructures of the austenite and duplex stainless steels with a possible transformation of the martensite phase induced by deformation, from the austenitic phase. Enayati, et.al produced nanocrystalline stainless steel powder by ball milling of austenitic stainless steel scrap chips and verified that the phase austenite in asreceived chips partially was transformed to the martensite phase after 100 hours milling ${ }^{19}$.

The aim of this work was to study the influence of the milling time and carbide addition on the behavior of a 
duplex stainless steel during high energy milling, and also characterizing the morphology of the particles, the particle size, the phases formed and the magnetic properties of the powder. The use of mechanical milling with the addition carbide is a novel method for the production of UNS S31803 powders from recycling chips for the manufacture of components in industrial sectors.

\section{Materials and Methods}

In this work, an UNS S31803 duplex stainless steel was used in the form of sheets, with a thickness of $5 \mathrm{~mm}$. The raw material for the research was obtained through machining in low speed and without lubricants to avoid contamination by oxygen and oil-solubles. From this process, it was possible to obtain the stainless steel alloy in the form of chips for the realization of subsequent milling process. To describe the average proportion of the alloy chip sizes, a stereoscopic macroscopic was used.

The milling was realized using a planetary ball mill for 20 hours in inert argon atmos-phere to avoid oxidation of the powders at a milling speed of $350 \mathrm{rpm}$ and a mass/ sphere relationship of $1: 15.3 \mathrm{wt} \% \%$ niobium carbide $(\mathrm{NbC})$ with initial size between $5 \mu \mathrm{m}$ and $15 \mu \mathrm{m}$ was added to the mill. Every 5 hours a sample of milled powder was taken for characterization, however in this work two milling times were chosen to analyze: 5 and 20 hours.

The characterization of stainless steel duplex milled powder was realized using a scanning electron microscope Carl Zeiss EVO MA15. In the secondary electron (SE) mode, the particle size variation and morphology of powder were analyzed. Using the back scatter electron (BSD) and energy dispersive $\mathrm{x}$-ray (EDS and Mapping) modes the distribution of $\mathrm{NbC}$ produced by Hermann C. Starck in matrix was evaluated.

Particle size distribution was performed in a Microtrac Bluewave S3500 to analyze size of powder with increasing milling time. An X-ray diffraction Panalytical X'pert PRO with $\mathrm{CoK} \alpha$ radiation was used for phase identification with sweeping angle of $45^{\circ}$ to $130^{\circ}$, step-size of $0.02^{\circ}$ and counting time per step of 2 second.

The characterization of the magnetic properties was performed in a vibrating sample magnetometer Lake Shore model VSM 7404. The amount of ferromagnetic phase was obtained as a function of saturation magnetization, using the formula ${ }^{20}$.

$$
C_{\alpha}=\frac{M_{s}}{133}
$$

Where: $\mathrm{C} \alpha$ is the ferrite amount and Ms is the saturation magnetization.

\section{Results and Discussion}

Figure 1 shows the characterization of a duplex stainless steel UNS S31803 in the form of thin and small chips short spiral type. It can be seen that the steel chips UNS S31803 processed by machining present a mean size of $2000 \mu \mathrm{m}$, and regions of surface plastic deformation originated by the machining tool.

Figure 2 shows the niobium carbide used. It was purchased from Herman. Figure 2 shows particle agglomerates with an average size of $20 \mu \mathrm{m}$, composed of particles of irregular morphology.

It can be seen in Figure 3 (a) that, after 5 hours of milling without the addition of carbides, the UNS S31803 stainless steel in the form of chips was transformed in particles with irregular morphology and dimensions around $600 \mu \mathrm{m}$. The encircled region in Figure 3(a) shows the shear area of a particle caused by plastic deformation and consequent displacement of crystal planes during process milling. For

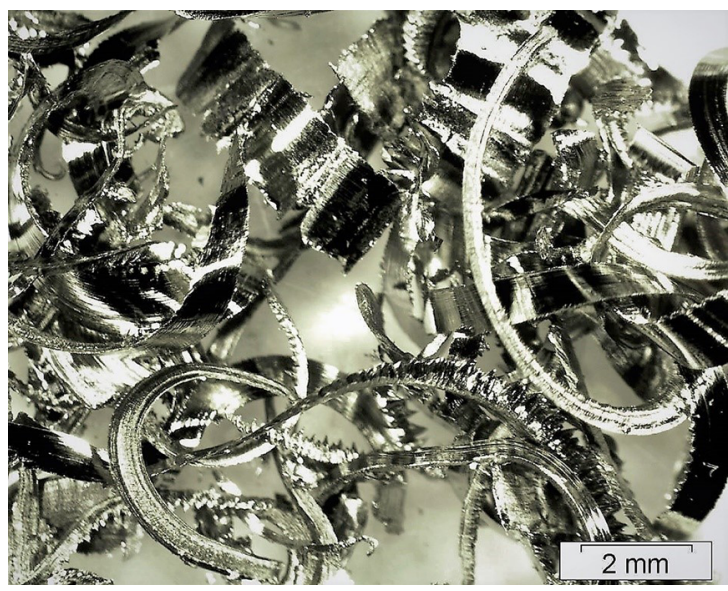

Figure 1. UNS S 31803 Duplex stainless steel in form of chips.

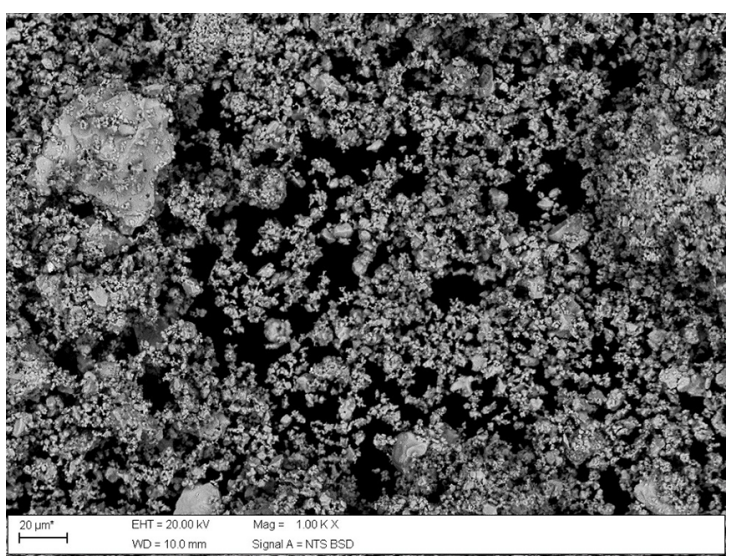

Figure 2. Powder of niobium carbide. 

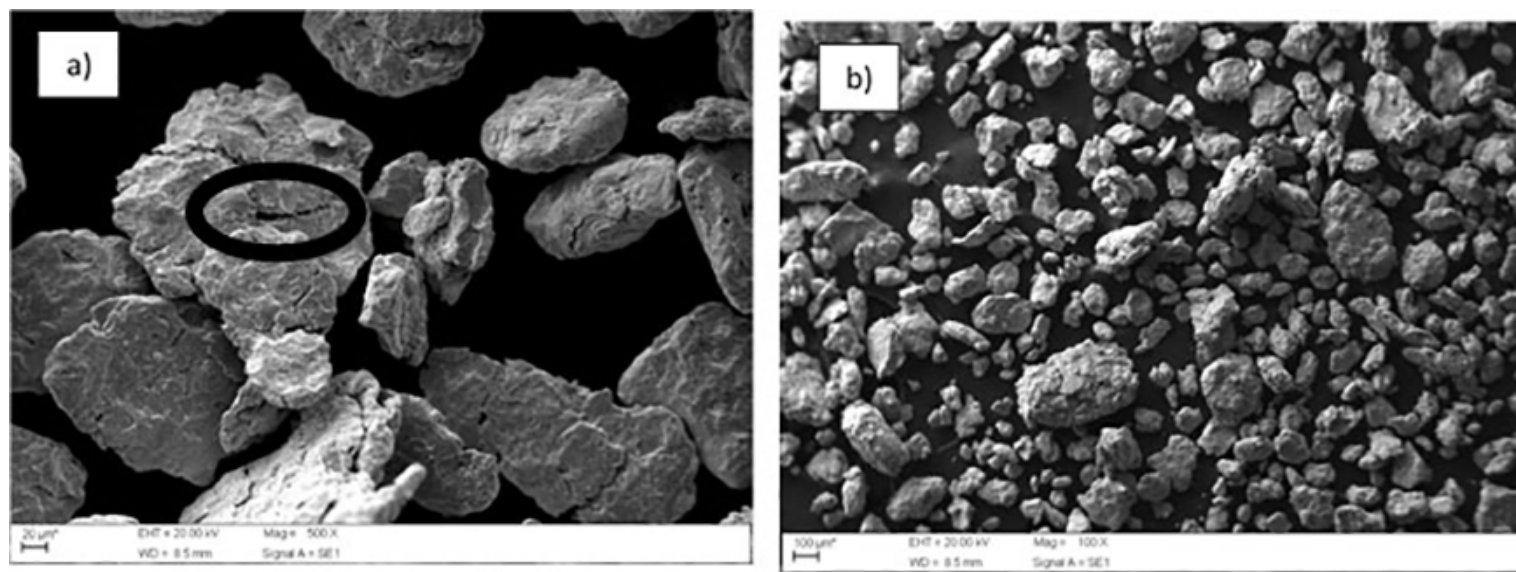

Figure 3. Particles of the duplex stainless steel after (a) 5 hours and (b) 20 hours of the milling.

the 20 hours milling, the particles remained in their irregular format, however, a decrease in particle size between $65 \mu \mathrm{m}$ and $400 \mu \mathrm{m}$, as can be seen in Figure 3(b). In the milling process of ductile-ductile system two main processes are distinguished: cold welding (due to ball-powder-ball impacts) and fracturing (due to brittleness induced by work hardening of powders $)^{17,21}$. The work hardening causes powders to become brittle, and the fracturing process becomes significant for longer milling time ${ }^{21}$.

For the milling with the addition of $3 \%$ of $\mathrm{NbC}$ after 5 hours, it was possible to obtain particles with sizes between $150 \mu \mathrm{m}$ and $500 \mu \mathrm{m}$ and a morphology with irregular particles (Figure 4a). With the increase of the milling time to 20 hours, it was possible to observe that the particles maintained the irregular shape with sizes between $60 \mu \mathrm{m}$ and $300 \mu \mathrm{m}$ (Figure $4 \mathrm{~b}$ ). Comparing the milling process of stainless steel in conditions without carbide and with addition of $3 \%$ of $\mathrm{NbC}$, under the same milling conditions, a decrease in particle size was observed obtaining particles of size smaller than $300 \mu \mathrm{m}$, which demonstrates an increase in the efficiency of the milling process.

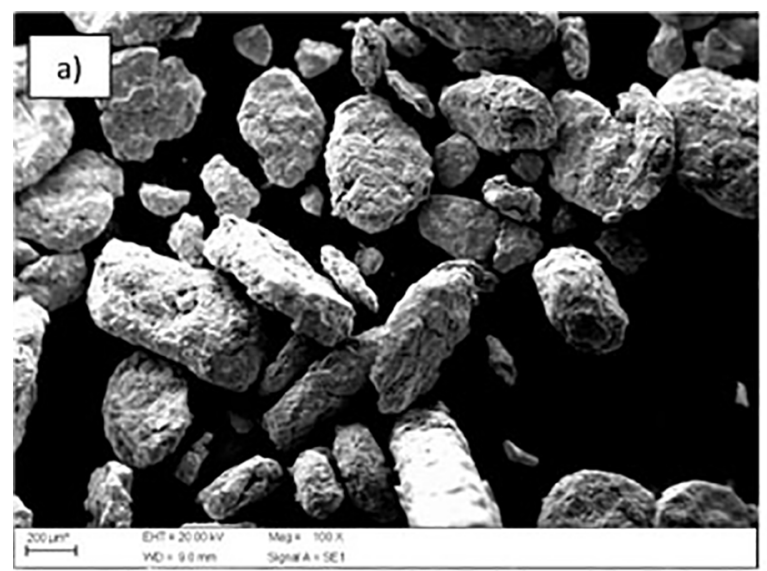

The cumulative particle size analysis curve seen in Figure 5 shows the limits of D10, D50, and D90 used as the acceptance criteria for the laser diffraction method. For example, it can be noted in the graph that for 20 hours milling with $\mathrm{NbC}$ addition the D50 is $115.8 \mu \mathrm{m}$, which means that $50 \%$ of particle sizes are below this value (i.e., the median diameter). Similarly, D10 and D90 are $65.3 \mu \mathrm{m}$ and 355.7 $\mu \mathrm{m}$, indicating that $10 \%$ of particles are below $65.3 \mu \mathrm{m}$ and $90 \%$ of particles are below $365.7 \mu \mathrm{m}$ respectively.

It can be seen in Table 1 the "D" values referring to D10, D50, and D90 and the size medium particles of the duplex stainless steel powders in function of the milling with and without carbide. From the analysis of the results, it is noted that the particle distribution for the D50 and D90 values is reduced by the addition of $3 \% \mathrm{NbC}$. These results show that the addition of $\mathrm{NbC}$ causes an increase in the efficiency of the milling process of duplex stainless steel. The addition of $3 \% \mathrm{NbC}$, for the same milling time of 20 hours, results in the reduction of the particle size of steel of the order of $20 \%$.

The Fig.6(a) presents the alloy analyzed using the backscattered electrons (BSD) mode where the brighter

Figure 4. Particles of the duplex stainless steel duplex with addition of $3 \% \mathrm{NbC}$ after (a) $5 \mathrm{~h}$ and (b) $20 \mathrm{~h}$ of milling.

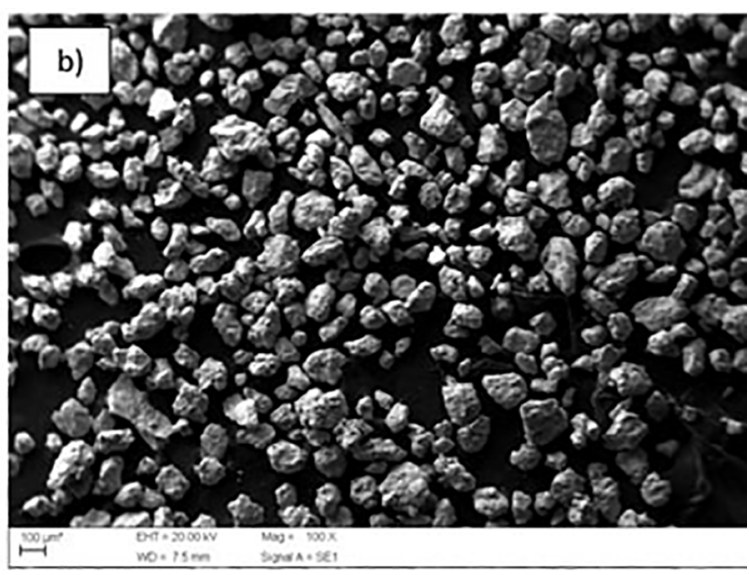




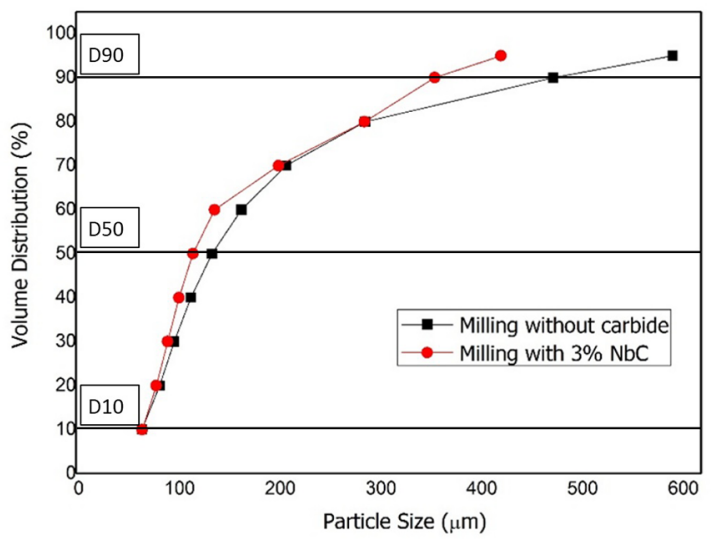

Figure 5. Volumetric distribution as a function of the particle size of the milling with and without addition of the $\mathrm{NbC}$.

spots represent the niobium because of the higher atomic weight of niobium. Figure $6 \mathrm{~b}$ shows the chemical elements obtained by dispersive energy spectroscopy (EDS). The corresponding elements of the duplex stainless steel were found as $\mathrm{Fe}, \mathrm{Cr}, \mathrm{Ni}, \mathrm{Si}$, as well as the elements constituting carbide niobium $\mathrm{Nb}$ and $\mathrm{C}$.

Figure 7 shows the magnetic behavior of the UNS S31803 duplex stainless steel under the following conditions: (a) as received; (b) after 5 hours of milling; (c) after 5 hours of milling with addition $3 \% \mathrm{NbC}$; (d) without addition of $3 \%$ $\mathrm{NbC}$ after 20 hours of milling; (e) with addition of $3 \% \mathrm{NbC}$ after 20 hours of milling.

Analyzing the results of Figure 7, it is noted that the samples after milling have increased saturation magnetization (MS) and the greater the time the greater the value obtained. The saturation magnetization depends only on the volume fraction of the magnetic phase, the increase in the value of the saturation magnetization is related to the transformation of austenite into martensitic induced by deformation. The longer the milling time the greater the formation of the martensitic structure.

The values obtained for the MS in the time of 20 hours were higher for milling without addition of carbide in relation to milling with addition of niobium carbide, resulting in a decrease of $12.8 \%$ of the values of saturation magnetization with addition of carbide.

Table 2 presents the values of saturation magnetization and ferromagnetic phase percentage (ferrite + martensite) obtained by equation (1), as well as the percentage of the phases present in duplex stainless steel. The material as received presents the ferrite and austenite phase. It is noticed that the increase of the milling time promotes the percentage increase of the ferromagnetic phase. The magnetization saturation increase with cold deformation process confirms the $\alpha^{\prime}$ generation by the $\gamma \rightarrow \alpha^{\prime}$ reaction ${ }^{20}$.

For the 5 hour milling time, an increase in the saturation magnetization values was observed in relation to the material as received, and consequently the amount of martensitic phase formed. The values obtained for the saturation magnetization in the milling samples with carbon addition are a little bit more than obtained for Ms in the grinding without carbide. Being that they are samples with different characteristics, the values obtained are different. Therefore, the 5 hour milling time did not substantially influence the saturation magnetization.

It can be observed that milling with the addition of niobium carbide, a material with characteristics of a paramagnetic material, reduces the transformation of austenite into martensite by deformation for a milling time of 20 hours. For milling with addition of carbide, the deformation generated during the process is smaller, and consequently the formation of a smaller amount of martensite induced by deformation occurs,

Table 1. Duplex stainless steel powders " $D$ ” values.

\begin{tabular}{lcccc}
\hline Duplex stainless steel particles after milling & $\mathrm{D} 10(\mu \mathrm{m})$ & $\mathrm{D} 50(\mu \mathrm{m})$ & $\mathrm{D} 90(\mu \mathrm{m})$ & Average size $(\mu \mathrm{m})$ \\
\hline Without carbide & 65.3 & 134.8 & 473.3 & 219.7 \\
With addition of 3\% NbC & 65.6 & 115.8 & 355.7 & 175.6 \\
\hline
\end{tabular}
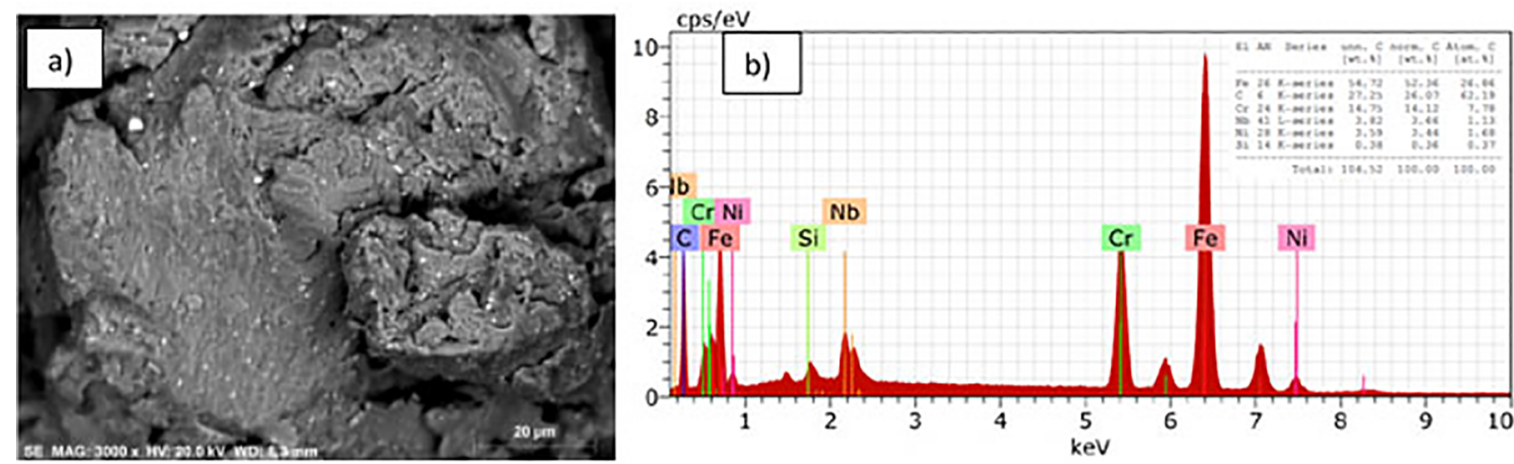

Figure 6. SEM image of the duplex stainless steel particles with NbC after 20 hours milling in the BSD mode (a); EDS analysis of duplex stainless steel for identifcation of main chemical elements (b). 


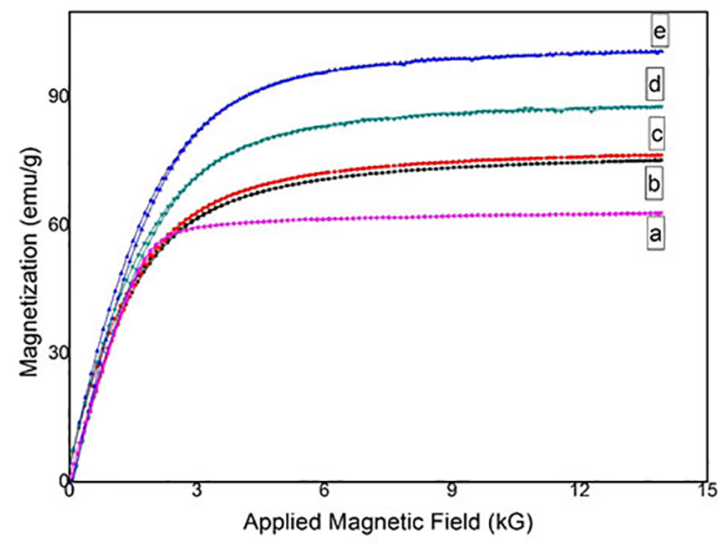

Figure 7. Magnetization curve as a function of the magnetic field applied in duplex stain-less steel samples under different conditions: (a) as received; (b) after 5 hours of milling without carbide; (c) adding $3 \% \mathrm{NbC}$ after 5 hours of milling (d) addition of $3 \% \mathrm{NbC}$ after 20 hours of milling; (e) after 20 hours of milling without carbide.

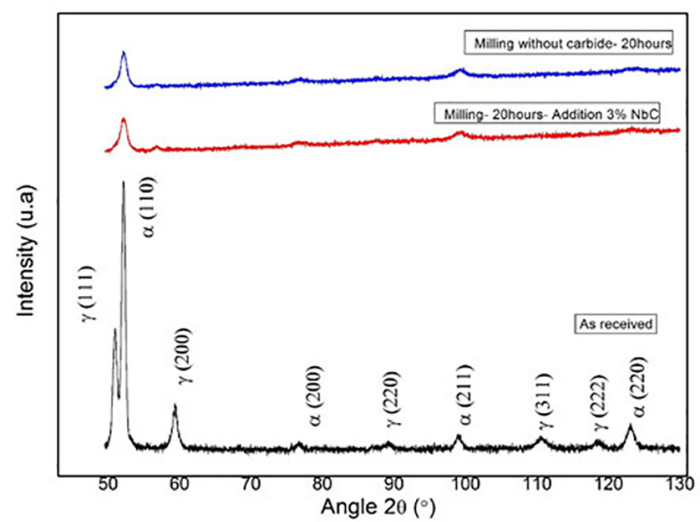

Figure 8. Diffractogram of stainless steel duplex UNS S31803 under the conditions: (a) as received; (b) after 20 hours of grinding without carbide; (c) after 20 hours of milling with addition of $3 \% \mathrm{NbC}$.

this may be due to the particles of the ceramic material collide with the particles of the metallic material, this kind of behavior could cause collisions that will weakness the region on the ductile particles that will lead to rupture the material by shear.

Figure 8 shows the X-ray diffraction results of the UNS S31803 duplex stainless steel under the conditions as received, after 20 hours of milling without addition of carbide and the powders after 20 hours of milling with addition of $3 \%$ of $\mathrm{NbC}$.

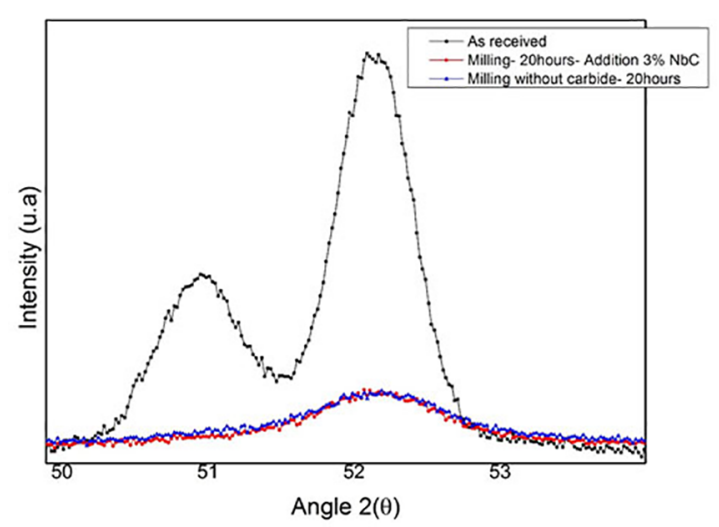

Figure 9. X-ray diffraction Figure 7 details showing only the ferrite, austenite and marten-site phase peaks for the regions of $2(\theta)$ between 50 and $54^{\circ}$.

Due to the milling process it is observed that peak intensity decreases and even disappears, and its width grows and the material is moving towards its amorphization due to the introduction of mechanical deformation in the crystalline planes resulting in particle and crystallite refinement. Measurements based upon the breadths and shapes of the X-ray reflections indicate that lattice distortion is predominantly responsible for the broadening. In some special cases, there is a large displacement of the cold-worked peak due to an overall expansion of the lattice, or to the presence of stealing faults ${ }^{22}$. Due to the detection limit of the x-ray apparatus the niobium carbide phase could not be found.

It can be seen in the diffractogram of Figure 9 that after the milling process, there was a decrease in the intensity and the broadening of the peaks of the ferritic (110) and austenitic (111) phase and the occurrence of the martensitic phase induced by the deformation. The peaks of the ferrite and martensite phases are not distinguished because both phases present the same reflection.

This broadening of the peaks of the material subjected to milling for 20 hours, as a function of non-uniform plastic deformation (microtension) of the crystalline lattice, from the stacking faults, shear planes, among other crystalline defects resulted from the decrease in particle $\operatorname{size}^{23}$. The generated deformation both by the process of the milling with and without addition of carbide caused the same degree of severity, showing a decrease and broadening equal to the phase peaks.

Table 2. Percentage of ferromagnetic phase and phases present in duplex stainless steel under different conditions.

\begin{tabular}{lccc}
\hline Conditions & Saturation magne-tization $(\mathrm{emu} / \mathrm{g})$ & (\%) Ferromagnetic phase & $(\%)$ Martensite \\
\hline As received & 62.1 & 46.7 & 0.0 \\
After 5 hours of milling & 75.2 & 56.5 & 9.8 \\
After 5 hours of milling $+3 \% \mathrm{NbC}$ & 76.4 & 57.4 & 10.7 \\
After 20 hours of milling & 100.6 & 75.6 & 28.9 \\
After 20 hours of milling $+3 \% \mathrm{NbC}$ & 87.8 & 66.0 & 19.4 \\
\hline
\end{tabular}




\section{Conclusion}

From the use of high energy ball milling process, it was possible to obtain powders of stainless steel duplex machined using discarded chips of material. Two parameters, carbide addition and milling time, were important to reduce the size of the powder, from the scale of milimters to the range of 60 to $600 \mu \mathrm{m}$. The milling time increased the values of saturation magnetization, due to deformation induced transformation of austenite into magnetic martensite. The addition of $3 \%$ $\mathrm{NbC}$ in the 20 hours of the milling reduces the transformation of austenite into martensite by deformation, in addition to reducing the average particle size by around $20 \%$.

\section{Acknowledgments}

The authors acknowledge The Brazilian agencies $\mathrm{CNPq}$, CAPES and FAPEMIG for financial support.

\section{References}

1. Shashanka R, Chaira D. Optimization of milling parameters for the synthesis of nano-structured duplex and ferritic stainless steel powders by high energy planetary milling. Powder Technology. 2015;278:35-45.

2. Ghosh SK, Mahat D, Roychaudhuri R, Modal R. Effect of rolling deformation and solution treatment on microstructure and mechanical properties of a cast duplex stainless steel. Bulletin of Materials Science. 2012;35(5):839-846.

3. Gunn RN. Duplex stainless steels-Microstructures, properties and applications. Cambridge: Woodlhead Publishing; 2003.

4. Fréchard S, Martin F, Clément C, Cousty J. AFM and EBSD combined studies of plastic deformation in a duplex stainless steel. Materials Science and Engineering: A. 2006;418(12):312-319.

5. Dobrzanski LA, Brytan Z, Grande MA, Rosso M, Pallavicini EJ. Properties of vacuum sintered duplex stainless steels. Journal of Materials Processing Technology. 2005;162-163:286-292.

6. Delforge DYM, Ferreira I, Silva CGR, Paris EAG, Marcelo AL, Novaes RH. Sinterização de uma mistura de cavaco de aço inoxidável com pó do mesmo material. Uma nova tecnologia para a reciclagem de metais? Rem: Revista Escola de Minas. 2007;60(1):95-100.

7. Bautista A, Velasco F, Campos M, Rabanal ME, Torralba JM. Oxidation Behavior at $900^{\circ} \mathrm{C}$ of Austenitic, Ferritic, and Duplex Stainless Steels Manufactured by Powder Metallurgy. Oxidation of Metals. 2003;59(3-4):373-393.
8. Gronotajski J, Chmura W, Gronostajski Z. Phases created during diffusion bonding of aluminum and aluminum bronze chips. Journal of Achivements in Materials and Manufacturing Engineering. 2006;19(1):32-37.

9. Kuffner BHB, Diogo WS, Amancio DA, Rodrigues G, Silva G. Evaluation of the milling efficiency increase of AISI 52100 steel using niobium carbide addition through high energy ball milling. Rem: Revista Escola de Minas. 2015;68(3):295-300.

10. Dias ANO, Silva A, Rodrigues CA, Melo MLNM, Rodrigues G, Silva G. Effect of High Energy Milling Time of the Aluminum Bronze Alloy Obtained by Powder Metallurgy with Niobium Carbide Addition. Materials Research. 2017;20(3):747-754.

11. Gubernat A, Zych L. The isothermal sintering of the singlephase non-stoichiometric niobium carbide $\left(\mathrm{NbC}_{1-x}\right)$ and tantalum carbide $\left(\mathrm{TaC}_{1-\mathrm{x}}\right)$. Journal of the European Ceramic Society. 2014;34(12):2885-2894.

12. Kosolapova TY. Carbides properties, production and applications. New York: Springer Publishing; 1971.

13. Madej M. Phase reactions during sintering of $M 3 / 2$ based composites with WC additions. Archives of Metallurgy and Materials. 2013;58(3):703-708.

14. Acchar W, Camara CRF, Cairo CAA, Filgueira M. Mechanical performance of alumina reinforced with $\mathrm{NbC}, \mathrm{TiC}$ and WC. Materials Research. 2012;15(6):821-824.

15. Woydt M, Mohrbacher H. Friction and wear of binder-less niobium carbide. Wear. 2013;306(1-2):126-130.

16. Alam SN. Synthesis and characterization of W-Cu nanocomposites developed by mechanical alloying. Materials Science and Engineering: A. 2006;433(1-2):161-168.

17. Suryanarayana C. Mechanical alloying and milling. Progress in Materials Science. 2001;46(1-2):1-184.

18. Gleiter H. Nanostructured materials: basic concepts and microstructure. Acta Materialia. 2000;48(1):1-29

19. Enayati MH, Bafandeh MR, Nosohian S. Ball milling of stainless steel scrap chips to produce non-ocrystaline powder. Journal of Materials Science. 2007;42(8):2844-2848.

20. Tavares SSM, Silva MR, Pardal JM, Abreu HFH, Gomes AM. Microstructural changes produced by plastic deformation in the UNS S31803 duplex stainless steel. Journal of Materials Processing Technology. 2006;180(1-3):318-322.

21. Canakci A, Varol T. A novel method for the production of metal powders without conventional atomization process. Journal of Cleaner Production. 2015;99:312-319.

22. Auld JH, Garrod RI. X-Ray Line-Broadening from Cold-worked Iron. Nature. 1952;169:579-580.

23. Cullity BD, Stock SR. Elements of X-Ray Diffraction. $3^{\text {rd }}$ ed. London: Pearson; 2013. 